\title{
Smart inverter operation in distribution networks with high penetration of photovoltaic systems
}

\author{
Emilio GHIANI $^{1}$, Fabrizio PILO ${ }^{1}$
}

\begin{abstract}
With the growing number and capacity of photovoltaic (PV) installations connected to distribution networks, power quality issues related to voltage regulation are becoming relevant problems for power distribution companies and for PV owners. In many countries, like Italy, this has required the revision of the standards concerning the connection to the public distribution network of distributed renewable generation. The new standards require a flexible operation of generation plants that have to be capable to change the active and reactive power dynamically in function of the network parameters (i.e. frequency and network local voltage) in local control or following external commands. Therefore, this paper investigates the use of smart inverter in a critical PV installation, where relevant voltage fluctuations exist. A case study, with real network parameters monitoring data and measurements, is discussed in the paper with the aim of showing how 'smart' features of new inverters can be implemented to increase PV plant integration in low voltage distribution networks.
\end{abstract}

Keywords Distributed generation, Photovoltaic installations, Voltage profile, Radial distribution networks, Measurements on power systems

CrossCheck Date: 6 October 2015

Received: 28 May 2015/Accepted: 6 October 2015/Published online: 31 October 2015

(C) The Author(s) 2015. This article is published with open access at Springerlink.com

$\triangle$ Emilio GHIANI

emilio.ghiani@diee.unica.it

Fabrizio PILO

pilo@diee.unica.it

1 Department of Electrical and Electronic Engineering, University of Cagliari, Cagliari, Italy

\section{Introduction}

The connection to active power distribution networks of the growing number and capacity of photovoltaic (PV) installations entails overcoming several technical challenges for distribution system operators (DSOs), that perceive PV systems has troublemakers for the electricity system. With increasing shares of renewable energy sources being integrated into the power distribution system, especially at low voltage (LV) and medium voltage (MV) levels, power quality issues related to voltage regulation and also stability problems are becoming relevant for DSOs, even though they are becoming to recognize that the use of severe standards designed to guarantee the disconnection of PV systems does not favorite integration of distributed generation (DG). More in detail, according to current standards, with no active management of distributed resources permitted, DG has to be disconnected in critical situations, (e.g. each time that voltage and frequency threshold are reached); this way of managing DG is no longer considered the right approach to obtain an effective DG integration and network operation. On the contrary, particularly in case of large amounts of DG in distribution networks, it may cause poor quality of power supply for the customers and risks on voltage and frequency regulation for DSOs and TSOs.

This paper presents some cases, with real network parameters monitoring data, when power distribution networks may result inadequate to integrate PV installations, due to voltage regulation problems caused by power fluctuations at the point of connection point. In fact, among all issues that can be caused by the high penetration of PV, voltage regulation is the most likely one, because it is directly correlated to the amount of reverse power flow during the PV system operation. Particularly in case of a 
weak power distribution network (e.g. rural or extra urban long MV or LV distribution lines with high $R / X$ ratios), the voltage variation may fall outside the admissible regulation band as defined by the connection standard, causing the intervention of the loss of mains relay and the unintentional disconnection of the plant.

Experimental data about monitoring of real operation of smart inverter had not been found in literature by the authors, despite the fact academic and industrial community is even more interested to know how smart inverter truly work on the field and if they will be fully active participants in network operations providing the same reliability as bulk generators [1]. Reference [1], for instance, underlined the need to test inverters volt/var controls or other forms of smart voltage regulation, as well as further PV inverters advanced grid support and features of reactive power control, active power control, grid management and dynamic grid support. Papers available in the literature are generally dedicated to computer simulations of the volt/var control methods [2, 3] or devoted to review PV inverters smart capabilities such as the capability to sense local conditions of voltage levels, frequency deviations and temperature, or receive commands and signals, which allow them to modify their active and reactive power output [4]. The study presented in this paper, provided with monitoring data of real network parameters, shows how 'smart' features of new inverters can be implemented to increase PV plant integration in existing LV active distribution networks with high PV penetration.

\section{Voltage regulation problems in active distribution networks}

The voltage regulation issues discussed in this paper are a consequence of the possible negative impact of DG on radial distribution networks [5].

The DG effects on weak distribution networks are well known, particularly the limitation to the integration of higher amounts of DG caused by voltage rise.

In fact, particularly in weak radial distribution networks, with long distances to be covered and high $R / X$ ratios in network impedance, the voltage rise can be considerable.

The voltage regulation problem is described by Fig. 1, where a generator and a load are connected at the end of the line.

The voltage variation in the feeder can be expressed by (1).

$\Delta V=V_{1}-V_{2}=\frac{R\left(P-P_{g}\right)+X\left(Q \pm Q_{g}\right)}{V}$

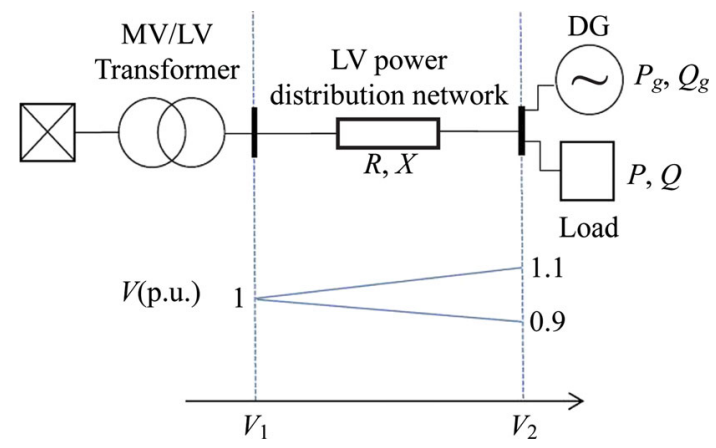

Fig. 1 Voltage rise effects in radial weak distribution networks

where $V_{1}$ is voltage at the begin of the feeder; $V_{2}$ the voltage at the end of the feeder; $R$ the resistance of the feeder; $X$ the reactance of the feeder; $P$ the active power absorbed by the load at the end of the feeder; $Q$ the reactive power absorbed by the load at the end of the feeder; $P_{g}$ the active power generated by DG at the end of the feeder; and $\pm Q_{g}$ the reactive power absorbed/generated by DG at the end of the feeder.

In case of no load condition $(P=Q=0)$, (1) can be rewritten as in (2) that shows the relationship between the injected power and the voltage at the point of common coupling (PCC).

$V_{2}=V_{1}+\frac{R\left(P_{g}\right)+X\left( \pm Q_{g}\right)}{V}$

According to (2), DG can provide voltage support to raise the $\mathrm{LV} V_{2}$ at the end of the feeder, but, in case of minimum/no load and high values of $R$, the magnitude of $V_{2}$ can result an overvoltage, limiting the capacity which can be installed, or, in general, the active power that can be injected at the end of the line. As in this study, the PV power generation could not only offset the load, but also cause reverse power flow through the distribution system with operational issues, including overvoltage and loss of voltage regulation.

Managing the active and reactive power generated by the PV system, in an intelligently coordinated way, can mitigate the adverse impact on the voltage at the end of the line, limiting overvoltage and improving voltage regulation [6].

\section{Italian standards for network connection and voltage regulation issues}

The Italian standards that regulate the connection to the public distribution networks are the standards CEI 0-21 [7], for LV connections, and CEI 0-16 [8] for MV and high voltage (HV) connections. 
The operation of a production plant in parallel with the distribution network must respect the following conditions defined by the standards [7, 8].

1) Do not cause disturbances to the service on the distribution network.

2) Stop immediately and automatically in the absence of power supply or if the mains voltage and frequency values are not within the values specified by the Distributor.

3) The parallel device of the production plant must not allow the parallel with the network in case of power failure or voltage and frequency values outside the values specified by the Distributor.

To ensure the separation of the production plant from the distribution network in case of power failure, an Interface Device (DDI) must be installed. The DDI is controlled by interface protection relay (SPI), that is a grid feeding monitoring relay with overvoltage protection (59), undervoltage protection (27), overfrequency protection $(81>)$, underfrequency protection $(81<)$, protection codes $59,27,81>, 81<$ are defined by ANSI /IEEE Standard C37.2 [9]. The mentioned protections are necessary to rapidly detect malfunctioning of the power distribution network and disconnect the DG plant of the customer by Italian standards CEI 0-16 and CEI 0-21. CEI 0-16 and CEI 0-21 settings must be consistent with EN50160 standard [10], related to voltage characteristics of electricity supplied by public distribution networks, which defines, describes, and specifies voltage quality criteria at the customers PCC in public LV, MV, and HV alternating current networks under normal operating conditions. Table 1 presents an overview about steady-state voltage criterion and permissible frequency deviations defined by EN50160.

The thresholds reported in Table 2 are therefore the protection interface setting values set by CEI 0-21 standard for PV systems, for the overvoltage and undervoltage protection in LV networks with nominal voltage 400/230 V [11]. Similar settings are defined by the CEI 0-16 for HV and MV networks.

According to CEI 0-21 requirements, the PV plant has to be disconnected from the distribution network when:

Table 1 EN50160 frequency/voltage supply characteristics

\begin{tabular}{ll}
\hline Parameter & Limit \\
\hline $\begin{array}{l}\text { Frequency } \\
\text { variations }\end{array}$ & $\begin{array}{l}49.5 \sim 50.5 \mathrm{~Hz} \text { during } 99.5 \% \text { of a year } \\
47.0 \sim 52.0 \mathrm{~Hz} \text { during } 100 \% \text { of the time }\end{array}$ \\
$\begin{array}{l}\text { Supply voltage } \\
\text { variations }\end{array}$ & $\begin{array}{c}\text { At least } 99 \% \text { of the 10-min root mean square } \\
\text { (RMS) values of the supply voltage shall be } \\
\text { between }-10 \% \text { and }+10 \% \text { of the systems } \\
\text { nominal voltage }\end{array}$ \\
& $\begin{array}{c}\text { None of the 10-min mean RMS values of the } \\
\text { supply voltage shall be outside the limits } \\
-15 \% \text { to }+15 \% \text { of the declared voltage }\end{array}$ \\
&
\end{tabular}

Table 2 CEI 0-21 over/under voltage protection settings

\begin{tabular}{lll}
\hline Protection threshold & Threshold values & Time of intervention \\
\hline $59 . \mathrm{s} 1$ & $253.0 \mathrm{~V}\left(1.10 V_{n}\right)$ & $\leq 3.0 \mathrm{~s}$ \\
$59 . \mathrm{s} 2$ & $264.5 \mathrm{~V}\left(1.15 V_{n}\right)$ & $<0.2 \mathrm{~s}$ \\
$27 . \mathrm{s} 1$ & $195.5 \mathrm{~V}\left(0.85 V_{n}\right)$ & $<0.4 \mathrm{~s}$ \\
$27 . \mathrm{s} 2$ & $92.0 \mathrm{~V}\left(0.4 V_{n}\right)$ & $<0.2 \mathrm{~s}$ \\
\hline
\end{tabular}

1) network voltage measured as an average on $10 \mathrm{~min}$ period is over $253 \mathrm{~V}(U>10)$ with time of intervention $\leq 3 \mathrm{~s}$;

2) network voltage is over $264 \mathrm{~V}$ with time of intervention $<0.2 \mathrm{~s}$;

3) network voltage is below $195.5 \mathrm{~V}$ with time of intervention $<0.4 \mathrm{~s}$;

4) network voltage is below $92 \mathrm{~V}$ with time of intervention $<0.2 \mathrm{~s}$.

A typical situation of disconnection of PV plants due to voltage regulation problems is shown in Fig. 2, which presents a cycling behavior of disconnection, automatic reclosing and further disconnection of the inverter, due to the intervention of the overvoltage protection. Voltage fluctuations may result in frequent unintentional disconnections of the PV system, causing accelerated detriment of the apparatus and reduction of energy production with related economic loss for the PV owner.

A detailed analysis on unintentional disconnection of PV plants connected to weak LV distribution network is presented in [12].

In particular, in Fig. 3, the daily registered voltage fluctuation in an existing PV plant is shown for a sunny day. In particular, during the PV production hours, the voltage is high and frequently above the upper voltage limit of the EN50160 standard (i.e., $V_{n}+10 \%$ ). In evening hours, after 17:00:00, when the residential customer increases the consumption, mostly due to the use of hot water obtained with electric boilers, the voltage is below the lowest EN50160 voltage limit (i.e. $V_{n}-10 \%$ ), when the production increases the voltage increases as well, and vice versa.

Figure 4 is related to a cloudy day, where the irradiation is low, and, consequently, PV production is low. The production in the morning is not sufficient to support the voltage above the LV limit of disconnection of the inverter, which, in this case, is disconnected due to the intervention of the 27.s1 protection.

\section{Smart inverter capabilities}

In order to overcome the described problem, the available smart capabilities of modern inverters can be used. 


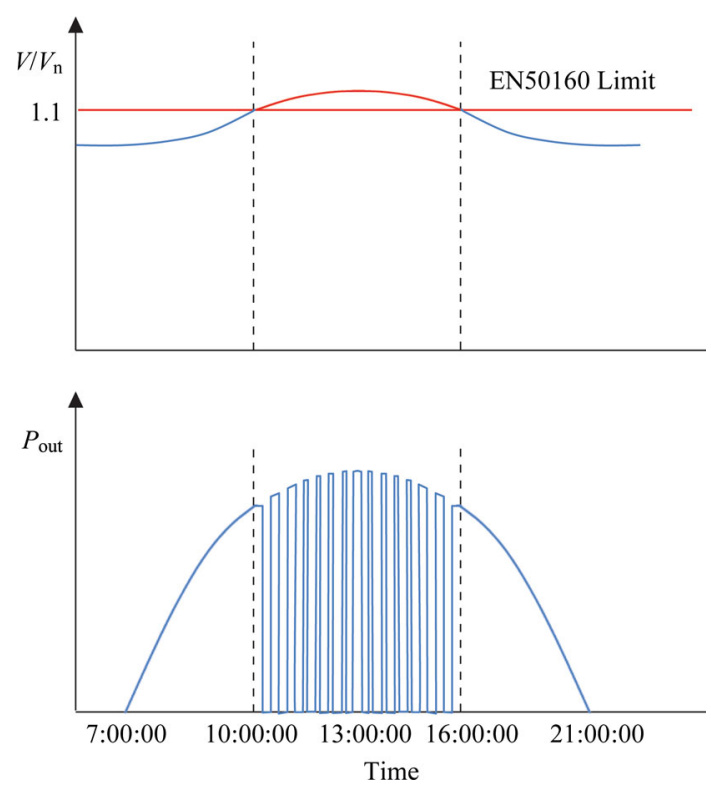

Fig. 2 Repeated network disconnections due to overvoltage

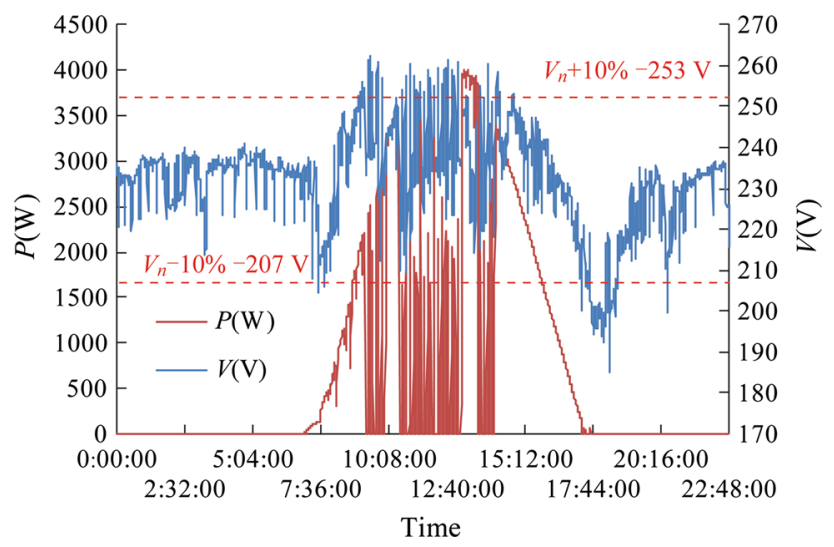

Fig. 3 Daily voltage fluctuations and disconnections—-sunny day

The performance of PV system in case of voltage regulation problems can be improved by the use of inverters with smart capabilities [13].

The most important characteristics are related to the possibility to dynamically regulate active and reactive power, and future developments of PV inverters will give the possibility to the distribution system operator to fully remotely control the generated active and reactive power of the PV plants.

Smart inverter capabilities currently available in commercial inverters are the following [2-4].

1) Set the automatic reduction of the active power generated from the inverter in case of overvoltage (generation curtailment); in this way the inverter will remain connected to the network avoiding continuous connections and disconnections resulting in higher plant energy production reductions.

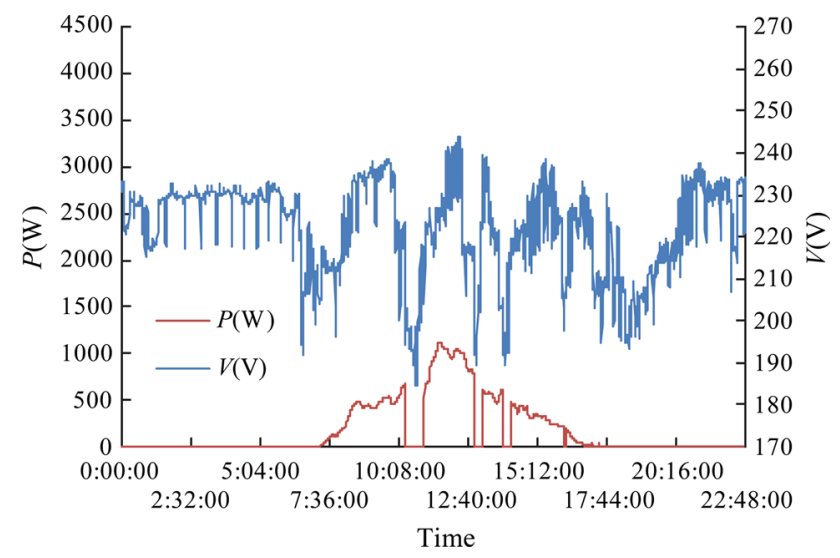

Fig. 4 Daily voltage \& power fluctuations-cloudy day

2) Operate at not-unity power factor the PV system, e.g. operate the inverter at power factor 0.9 inductive, in this way the inverter absorbs reactive power and the voltage is reduced; this way of operation is considered by CEI $0-21$ but requires approval by DSO;

3) Adopt a volt/var control method to provide adequate voltage support for voltage variations resulting from changes in PV output, and this approach could be also used during cloud passages that cause a sudden drop in active power. The inverter volt/var control responds to the sudden drop in voltage by injecting additional reactive power.

\subsection{Active power curtailment}

Active power curtailment consists in limiting/curtailing the active power generated by the inverter in order to reduce the voltage at the PCC of the PV plant.

The diagram in Fig. 5 shows the expected effects of the limitation on the delivered power and on the voltage at the PCC.

The activation of the limitation of the active power is for grid voltage values close to $110 \%$ of the nominal value $(U>10)$ (CEI 0-21). This setting automatically limits the inverter output power when the grid voltage is close to the protection voltage threshold $(U>10)$ avoiding inverter disconnection.

The activation of the limitation reduces the active power fed to the grid by the system, but it may improve the productivity, since the inverter remains connected to the grid avoiding continuous connections and disconnections.

\subsection{Reactive power management $\cos (\varphi)=f(P)$}

Inverters have several possibilities to influence the voltage at the PCC managing reactive power and without losing active power generated. Through supplying reactive power, the voltage in the grid can be raised by delivering 

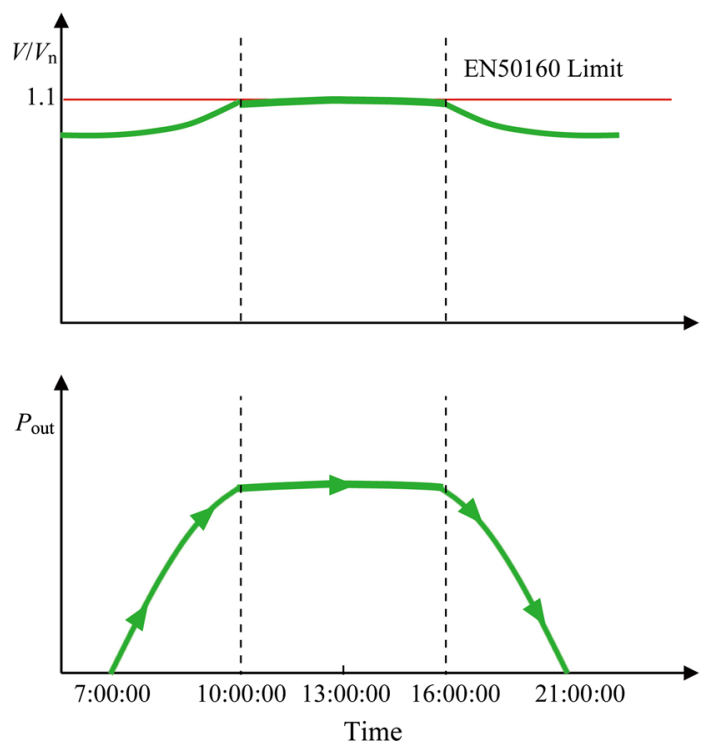

Fig. 5 Active power curtailment for voltage smoothing

reactive power, and it can be lowered by consuming reactive power. There are several ways to control the reactive power with smart inverters. The possibilities range from the simplest way, a fixed displacement factor $\cos (\varphi)$ to an optimized and fully configurable voltage dependent reactive power control functionality.

Reactive power management $\cos (\varphi)=f(P)$ showed in Fig. 6 consists of reducing the $\cos (\varphi)$ with the increment of the active power generated. In this operation mode, the smart inverter works as an inductive load absorbing reactive power from the grid. Consequently, the voltage at PCC can be reduced. The $\cos (\varphi)$ is set as a function of the output power $P$ provided by the inverter, accordingly to the setpoints defined by the user, as shown in Fig. 6 .

\section{3 volt/var reactive power management}

In volt/var reactive power management mode, the local control of the inverter will provide an amount of reactive

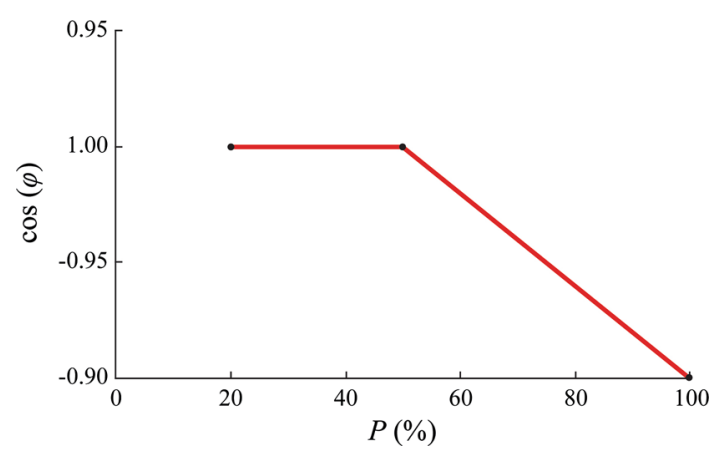

Fig. 6 Reactive power management $\cos (\varphi)=f(P)$

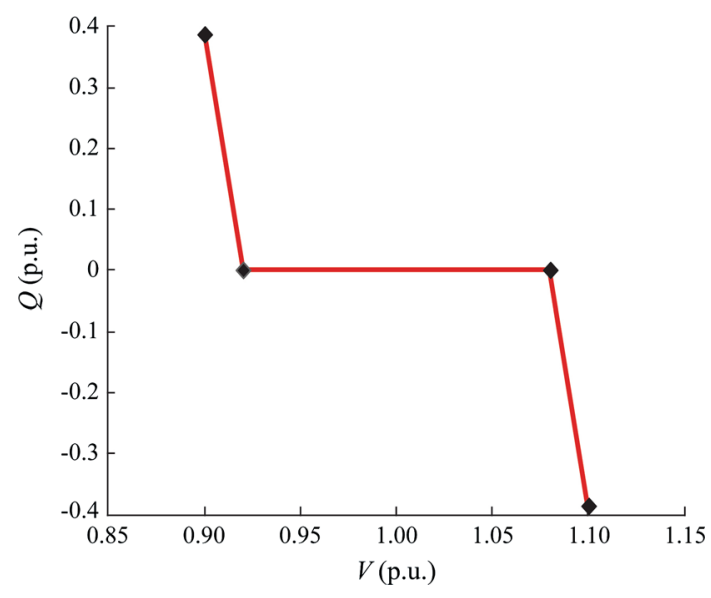

Fig. 7 Reactive power management for voltage regulation

power $Q$ as a function of the grid voltage, accordingly to the setting points defined by the user, which is shown in Fig. 7.

In combination with communication, the local control functions of Figs. 6 and 7 can be dynamically configured during the operation. It is possible that even the most sophisticated reactive power control modes are not enough to keep the grid voltage within the required limits. Especially in LV networks, active power has the biggest influence on the voltage. Consequently, modifying only the reactive power of the PV inverter cannot prevent from overvoltage. In these cases only the reduction of produced power can prevent from complete disconnection.

\section{Case study of smart inverter operation}

A case study is presented and discussed in order to show how 'smart' features of new inverters can be implemented to improve PV plant integration in an existing LV active distribution networks with high PV penetration.

\subsection{Description of PV plant}

The plant under study is constituted by $250 \mathrm{PV}$ modules CEEG $260 \mathrm{Wp}$, and 3 inverter ABB TRIO-20.0-TLOUTD-20 kW, $400 \mathrm{~V}$; the nominal power of the PV plant is then $250 \times 260 \mathrm{Wp}=65 \mathrm{kWp}$.

A simplified PV plant scheme and the single line wiring to distribution network are provided in Fig. 8.

The plant is located in an extra urban area and connected by a LV network. The customer is positioned at more than $1 \mathrm{~km}$ from the distributor's MV/LV secondary substation. Along the LV network path, between the DSO substation and the customer, several additional passive customers are also connected. 


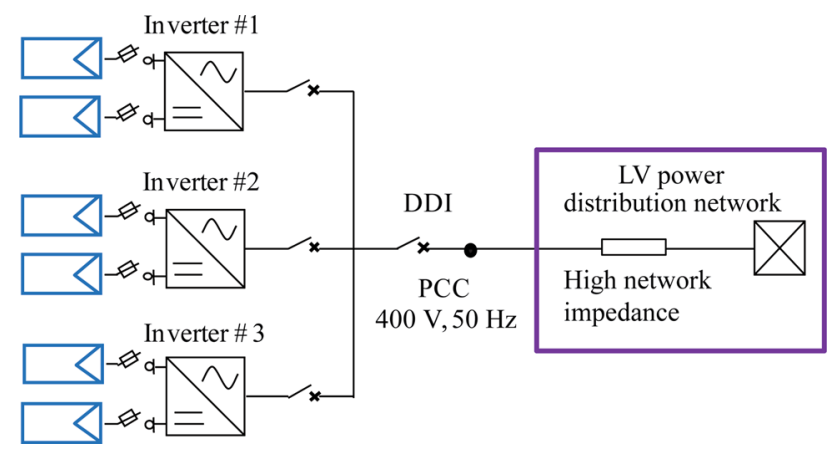

Fig. 8 Scheme of PV plant

\subsection{PV plant behavior without smart inverter operation}

Just a few days after the plant start-up, the monitoring system revealed some malfunctioning of the PV plant due to frequent disconnections during the hours with the highest production.

Figure 9 is related to the period before the smart operation of the inverter was activated. Figure 9 shows the behavior of the three inverters. It is possible to see that the inverter \#1 is disconnected from the network due to excessive voltage at the PCC. In fact, when the PV plant inverters inject considerable real power into the main grid, it drives local voltages up and outside limits.

The disconnection of the inverter \#1 results in the reduction of the voltage at the PCC, and the remaining inverters \#2 and \#3 remain connected to the network with a production that follows the same behavior of the solar radiation.

In particular, the internal electronic interface control of the inverter \#1 commands the disconnection due to excessive overvoltage. As depicted in Fig. 10, voltages

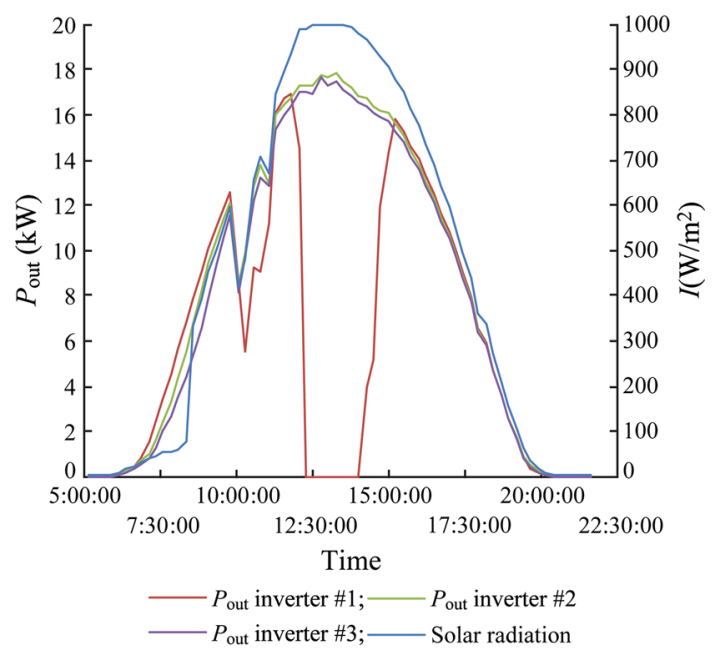

Fig. 9 PV plant operation (no smart operation, three inverters) near the limit of $253 \mathrm{~V}$ were registered since 10:00:00-15:15:00.

Figure 10 shows with more detail the behavior of inverter \#1 in the time interval 12:15:00-14:00:00 and cannot produce energy. Unfortunately, the monitoring system had no enough resolution to record the repeated disconnection from the grid, but they are confirmed by the fault log which can be downloaded from the inverter status operation record.

\subsection{PV plant behavior with smart inverter operation}

In order to overcome the problem of disconnection, the inverters are set to operate as smart inverter with dynamic operation depending on the voltage parameter at the PCC.

Figure 11 refers to the same plant after the activation of the smart inverter operation. The figure shows the behavior of the three inverters, and it is possible to see that the inverter \#1 is not disconnected from the network, but the active power is significantly reduced to maintain the grid voltage below the disconnection threshold. The inverters \#2 and \#3 follow normally the same behavior of the solar radiation, and, in this case, are not involved in active power curtailment.

The power curtailment is proportional to the $R / X$ ratio of the distribution network. This means, in case the $R / X$ ratio would be very high, the inverter could reduce the power up to zero but still remaining connected to the grid.

The power injection curtailment is applied consecutively to the three inverters, which means if the reduction to zero of the active power injected into the grid by inverter \#1 would not be sufficient to maintain the grid voltage below the disconnection threshold, the inverter \#2 would start to reduce its active power to provide its contribution to grid

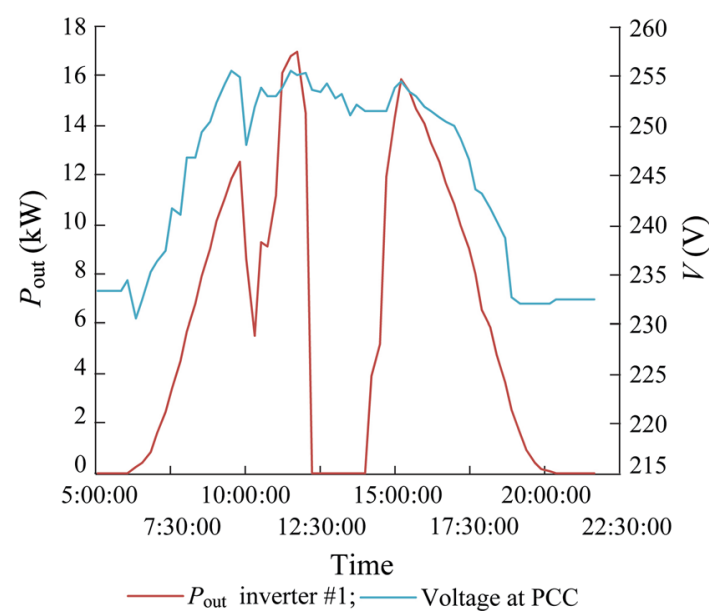

Fig. 10 PV plant operation (no smart operation, inverter \#1) 


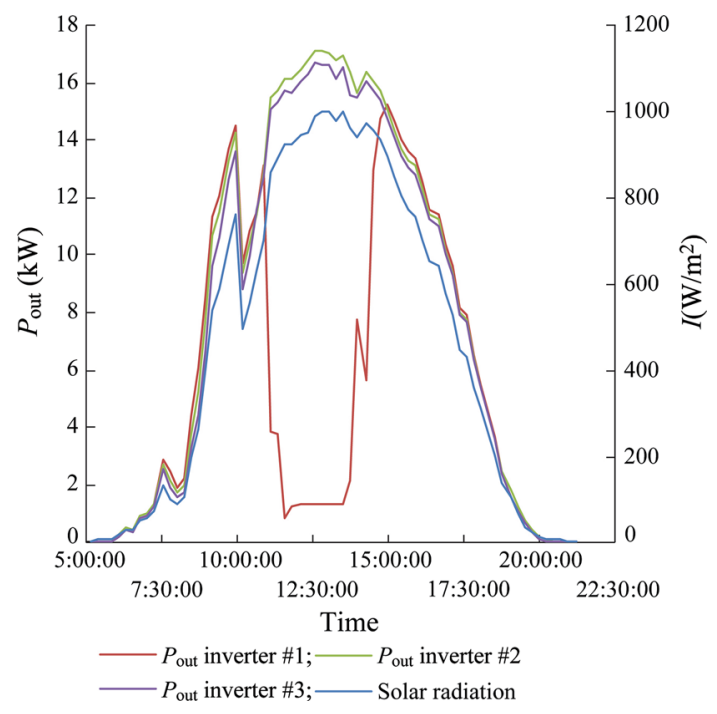

Fig. 11 PV plant operation (smart operation, three inverters)

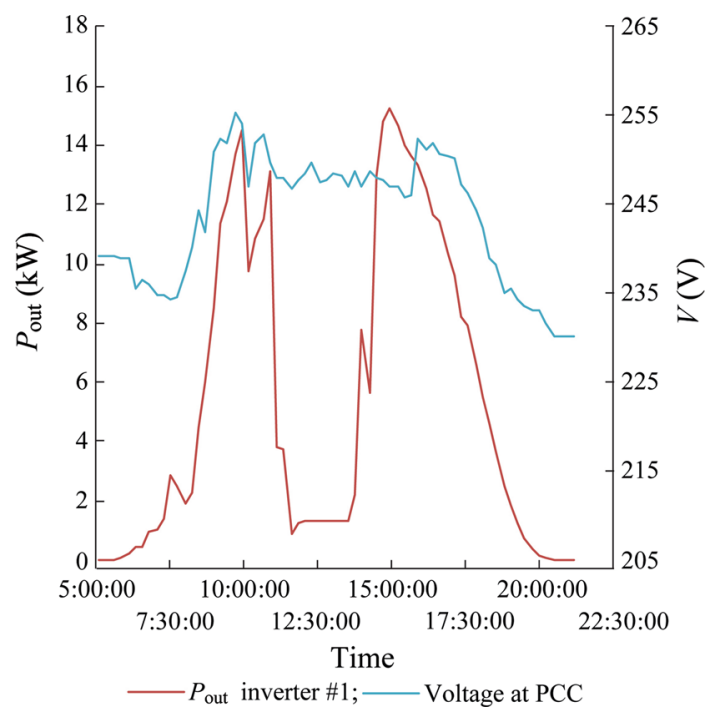

Fig. 12 PV plant operation (smart operation, inverter \#1)

voltage reduction. The same happens for inverter \#3 in case the reduction of the injected power to zero of inverter \#2 would not be sufficient to maintain the voltage below the disconnection threshold. This has been obtained by changing the activation threshold settings for dynamic operation of the inverters.

Figure 12 shows with more detail the behavior of inverter \#1 and the voltage during the period of higher production of the plant. The inverter remains connected, and the voltage is lowered within the tolerable limit. It is important to underline that during the observation period after the activation of the smart operation, the inverter \#1 showed no disconnection due to HV at PCC.
This specific real case study is related to a radial weak network with very high $R / X$ ratio. As pointed in section 4.3 , when $R / X$ ratio is very high, modifying the reactive power of the PV inverter cannot prevent from overvoltages, and the volt/var regulation can be ineffective. Unfortunately, in this example it is not possible to find a case when the smart operation ca be shown considering the volt/var reactive power management.

\section{Conclusion}

The paper provides a comprehensive view on voltage regulation problems in LV distribution networks with high penetration of $\mathrm{PV}$, providing experimental data on real smart inverter operation and demonstrating the effectiveness of local controls.

In LV distribution networks, when high PV penetration in distribution networks exist, voltage regulation problems may occur, and smart features of modern inverters can be implemented to improve the voltage profile and the whole performances of PV system.

Results of this investigation confirm that the use of active and reactive power management may permit better integration of PV inverters in distribution networks. In addition, the smart operation of the inverters may prevent accelerated detriment of the system due to frequent disconnection, and, consequently, allow the increment of energy production with economic advantages for the PV owner.

Open Access This article is distributed under the terms of the Creative Commons Attribution 4.0 International License (http:// creativecommons.org/licenses/by/4.0/), which permits unrestricted use, distribution, and reproduction in any medium, provided you give appropriate credit to the original author(s) and the source, provide a link to the Creative Commons license, and indicate if changes were made.

\section{References}

[1] Brundlinger R, Strasser T, Lauss G et al (2015) Lab tests: verifying that smart grid power converters are truly smart. IEEE Power Energy Mag 13(2):30-42

[2] Smith JW, Sunderman W, Dugan R et al (2011) Smart inverter volt/var control functions for high penetration of PV on distribution systems. In: Proceedings of the 2011 IEEE PES power systems conference and exposition (PSCE'11), Phoenix, AZ, USA, 20-23 March 2011, 6 pp

[3] Reno MJ, Broderick RJ, Grijalva S (2013) Smart inverter capabilities for mitigating over-voltage on distribution systems with high penetrations of PV. In: Proceedings of the IEEE 39th photovoltaic specialists conference (PVSC'13), Tampa, FL, USA, 16-21 June 2013, pp 3153-3158

[4] Bründlinger R (2013) Smart inverter technology for high PV penetration. In: Proceedings of the international workshop on PV and the electricity grid, Sydney, Australia, 26 November 2013, 27 pp 
[5] Barker PP, de Mello RW (2000) Determining the impact of distributed generation on power systems-I: Radial distribution systems. In: Proceedings of the 2000 IEEE Power Engineering Society summer meeting: vol 3, Seattle, WA, USA, 16-20 July 2000, pp 1645-1656

[6] Celli G, Ghiani E, Loddo M et al (2005) Voltage profile optimization with distributed generation. In: Proceedings of the 2005 IEEE Russia power tech conference, St Petersburg, Russia, 27-30 June 2005, 7 pp

[7] CEI 0-21:2012 (2012) Technical rules for the connection of active and passive users to the LV networks of electricity distribution companies. Italian standard

[8] CEI 0-16:2012 (2012) Technical rules for the connection of active and passive users to the HV and MV networks of electricity distribution companies. Italian standard

[9] ANSI/IEEE Std C37.2-2008 (2008) Standard for electrical power system device function numbers, acronyms, and contact designations

[10] EN 50160-2007 (2007) Voltage characteristics of public distribution systems

[11] Braun M, Stetz T, Bründlinger R et al (2012) Is the distribution grid ready to accept large-scale photovoltaic deployment? State of the art, progress, and future prospects. Prog Photovolt 20(6):681-697

[12] Ghiani E, Pilo F (2014) Investigation on unintentional disconnection of photovoltaic plants in LV distribution networks. In: Proceedings of the IEEE 16th international conference on harmonics and quality of power (ICHQP'14), Bucharest, Romania, 25-28 May 2014, pp 39-43
[13] Twining E, Holmes DG (2003) Voltage profile optimization for weak distribution networks. Aust $\mathrm{J}$ Electr Electron Eng 22(3):179-186

Emilio GHIANI received his PhD degree in Electrical Engineering and Computer Science in 2005 from University of Cagliari, where currently he is an Assistant Professor at the Department of Electrical and Electronic Engineering (DIEE). His research focuses mainly on the development of methodologies and tools for decision making process in planning and operation of power distribution networks with large penetration of distributed energy resources. His research interests include co-simulation of power and communication system related to smart grid operation (e.g., automatic control of voltage and frequency, demand response and management of storage devices).

Fabrizio PILO is Full Professor at the Department of Electrical and Electronic Engineering (DIEE) of the University of Cagliari from October 2014. He earned the PhD degree from the University of Pisa in 1998. In 1996, he became Assistant Professor and in 2001 Associate Professor at DIEE. Prof. Pilo has 20-year experience in the field of power distribution planning and development. He was one of the advisors of the Italian Regulatory Agency with reference to the implementation of Smart Grid in the Italian power system. He is the Chairman of the CIRED Session 5, Distribution System Development and Convener of the CIGRE WG C6.19-Planning for Active Distribution Systems. 